\title{
Litigation in thyroid cytology and histopathology in England: a very brief overview
}

\author{
David N. Poller \\ Department of Pathology, Queen Alexandra Hospital, Cosham, Portsmouth, UK \\ Correspondence to: Dr. David N. Poller, MD, FRCPath. Consultant Pathologist, Department of Pathology, Queen Alexandra Hospital, Cosham, \\ Portsmouth, PO6 3LY, UK. Email: david.poller@porthosp.nhs.uk.
}

\begin{abstract}
This brief review discusses legal issues in thyroid cytology and histopathology in England. The principal risks in thyroid cyto/histopathology are either underdiagnosis of a malignant condition as benign, overdiagnosis of a benign condition as malignant, or the failure to recognise or the overdiagnosis as malignant of a benign or inflammatory condition. There are multiple diagnostic pitfalls in both cytology and histopathology and these are reasonably well documented. The interobserver reproducibility as assessed by kappa statistics of some of the major criteria for malignancy, specifically papillary-type nuclei in the diagnosis of papillary thyroid carcinoma, capsular invasion or vascular invasion are comparatively poor hence diagnoses of well differentiated papillary or follicular carcinoma may often be to some extent subjective. This article reviews the current legal situation in England discussing recent legal case precedents with a suggestion for improving communication and the preoperative consent process for patients.
\end{abstract}

Keywords: Thyroid; cytology; histopathology; error; clinical negligence

Submitted Aug 16, 2019. Accepted for publication Feb 17, 2020.

doi: 10.21037 /gs.2020.02.15

View this article at: http://dx.doi.org/10.21037/gs.2020.02.15

\section{Introduction}

The field of thyroid cytopathology and histopathology is one of the most subjective areas of diagnosis in pathology practice. Based on the personal experience of the author diagnostic criteria for thyroid disease and thyroid cancer are reviewed from a UK perspective, with an emphasis on English law.

In thyroid cytopathology and histopathology the principal risks are either under diagnosis of a malignant condition as benign, or overdiagnosis of a benign or inflammatory condition as malignant. The diagnostic pitfalls in cytology and histopathology are well known and are well documented $(1,2)$. Litigation in cytopathology or histopathology may take place when a patient suffers a cytological or histopathological misdiagnosis (3). The diagnostic criteria for malignancy in thyroid disease are based primarily on morphology; that is the nature and type of the tumour cells seen, frequently supported by immunohistochemical findings, and sometimes by molecular pathological findings. In 2019 however the diagnostic criteria for benign and malignant thyroid conditions are still based almost exclusively on morphological assessment of either cytology slides prepared conventionally with Papanicolaou and Giemsa stains, liquid-based cytology specimens, or haematoxylin and eosin stained formalin-fixed paraffin-embedded tissue sections, core biopsies, or surgical excision specimens (4).

Decision-making in thyroid disease both in cytopathology and histopathology is not a binary yes/no decision is but is often based on the balance of probabilities. Practitioners of thyroid disease are well aware of this but patients may not be. Below is a list of some of the problem areas in thyroid cytohistopathology with data on interobserver reproducibility.

\section{Papillary-type nuclei: diagnosis of papillary thyroid carcinoma and NIFTP}

The diagnosis of papillary-type nuclei is subjective. This 
is borne out by studies showing significant interobserver variation in the diagnosis of encapsulated follicular variant of papillary carcinoma (5-7). Similarly in the diagnosis of non-invasive follicular thyroid neoplasm with papillarylike nuclei (NIFTP), the degree interobserver variation for the diagnosis of NIFTP versus follicular adenoma has been shown in published studies to be significant $(8,9)$. The diagnosis of papillary carcinoma can be confirmed by molecular testing for BRAF V600E if this is available, as this mutation is almost $100 \%$ specific for papillary thyroid carcinoma and its variants, although the sensitivity for papillary thyroid carcinoma is much lower as many papillary thyroid carcinomas do not show BRAF V600E mutations (10).

\section{Diagnosis of thyroid carcinoma in formalin-fixed paraffin-embedded sections}

Some of the problems of diagnosis of thyroid carcinoma are highlighted in the excellent review by Rosai et al. (2). The authors list multiple diagnostic pitfalls, including tumour herniation through the thyroid capsule simulating capsular invasion, reactive vascular proliferation simulating vascular invasion, pseudo-infiltration of skeletal muscle by benign thyroid tissue, parasitic nodules simulating metastatic thyroid carcinoma, nuclear clearing in benign conditions resembling the nuclear changes of papillary thyroid carcinoma, benign nuclear bubbles simulating nuclear pseudoinclusions papillary thyroid carcinoma, benign papillary structures simulating papillae of papillary thyroid carcinoma, solid cell nests simulating papillary microcarcinoma, ectopic thymic tissue simulating metastatic carcinoma, fibrosing thyroiditis simulating papillary microcarcinoma, psammoma-like bodies in Hurthle cell neoplasms simulating some psammoma bodies of papillary thyroid carcinoma, and paucicellular variant of anaplastic thyroid carcinoma simulating Riedel's thyroiditis (2).

\section{Presence or absence of capsular or vascular invasion in the diagnosis of follicular thyroid carcinoma}

The diagnosis of well differentiated follicular thyroid carcinoma rests principally on the identification of invasion of the thyroid capsule and/or of surrounding tissue. However the published data shows that the interobserver reproducibility of capsular and vascular invasion in the thyroid is relatively poor. In one study which examined the level of interobserver agreement the interobserver kappa statistic for capsular invasion was 0.27 and for vascular invasion was 0.20 , thus confirming that assessment of capsular or vascular invasion shows poor interobserver reproducibility and is therefore often subjective (11).

\section{Interobserver variation in the reporting of subcategories using thyroid FNA terminologies}

There is significant interobserver reproducibility in assessment of thyroid FNA cytology. Thyroid cytology requires both qualitative and quantitative interpretation of microscopic features. The interobserver reproducibility of the different subcategories of the various FNAC terminology systems is variable (12-17). Studies show at best moderate and sometimes very poor interobserver reproducibility for some of the FNAC sub-categories, particularly for Thy $3 \mathrm{a}(\mathrm{k}=0.11)$ equivalent to atypia of undetermined significance/follicular lesion of undetermined significance (AUS/FLUS)-Bethesda category III. A fine-needle aspirate categorised as Thy $3 \mathrm{a}$ or Bethesda category III by one individual cytopathologist might be categorised as category II/Thy 2 (Benign) or category IV/ Thy $3 \mathrm{f}$ (Follicular Neoplasm or Suspicious for a Follicular Neoplasm) by another equally skilled and competent cytologist (17).

As an aid to assist cytopathologists and histopathologists 12 recommendations can be utilised to potentially reduce the risk of misdiagnosis in thyroid FNAC and histopathology (Table 1). These factors are discussed elsewhere in much greater depth (18). The propensity for patients to enter into litigation is referred to as the so-called 'malpractice climate'. It is difficult to be clear as to the exact causes. A recent study suggests that for thyroid cancer diagnosis in the United States there is an association between state-level thyroid cancer incidence, and malpractice pay-out rates for thyroid cancer but not for breast, prostate, colon or lung cancer (19). Conversely in Japan thyroid patients rarely sue clinicians or pathologists (personal communication K Kakudo, 2019).

In English law the test of clinical negligence is the Bolam test (20), although this has been modified and refined over the years. The Bolam test in essence states that a medical action or diagnosis is defensible if a responsible body of medical opinion would have made that diagnosis or undertaken a particular clinical action. However this is also been refined over the years so that in English law where there is a disagreement between two experts, one 
Table 1 List of recommendations that may improve clinical decision making and may reduce the scope for diagnostic error in thyroid fine-needle aspiration cytology and histopathology

Use a standardised reporting terminology for thyroid fine-needle aspiration cytology

Understand and explain to service users the limitations of thyroid fine-needle aspiration cytology and the standardised thyroid cytology reporting terminology utilised

Review all the relevant clinical and ultrasound findings if feasible

Include the risk of malignancy in all thyroid cytology reports if feasible

Collect data to calculate the local risk of malignancy if this is possible

Accept that non-diagnostic fine-needle aspirations will include small numbers of carcinomas, comprising mainly cystic papillary thyroid carcinoma

Rapid on site evaluation and/or educational sessions for aspirators can reduce the rate of non-diagnostic aspirates if the number of non-diagnostic aspirates is high

Know the relevant diagnostic pitfalls of both thyroid cytopathology and histopathology

Use special immunohistochemical and molecular techniques that are evidence-based

Second opinions are very valuable; in-house or inter-institutional

Multidisciplinary case discussion prior to surgery or therapy is invaluable

Manage patient and clinician expectations of thyroid cytopathology and histopathology

acting for a plaintiff, the other acting for defendant unless this disagreement can be rationally explained the judge and the court may make the final decision (21). In practice this issue is most important in cases of 'diagnostic miss' that is where a malignant condition or a condition which requires further investigation or treatment is missed and so diagnosed as benign or not requiring further treatment. If it can be shown that the reporting cytopathologist or histopathologist missed some abnormal cells and/or did not recommend a specific form of treatment and the plaintiff's expert and the defendant's expert both agree that this is an error, this diagnostic error might well be considered indefensible in English law (21). This might be despite the fact that the relevant cytology smear or histology section only contains a tiny number of the relevant abnormal cells, and despite the fact that the review by both plaintiff's and defendant's expert is subject to the cognitive bias that both experts know that the relevant cytology or histology smear shows an abnormality.

The second issue in English law is that of consent to diagnosis and treatment with the precedent for this being an obstetric case of shoulder dystocia, The Montgomery case (22). The result of this UK Supreme Court ruling is that doctors practising in England must now before any procedure or operation give a very detailed informed consent process to the patient including all risks of potential harm or adverse outcome if these are ones that a patient might reasonably wish to be informed of. If the medical practitioner fails to do this and then a patient suffers harm or complication of a procedure or surgery and the patient has not been forewarned of this particular risk, even if this risk is very low, this would be most likely indefensible. A recent review has shown that thyroid surgery in England is subject to significant numbers of medicolegal claims, hence the issue of full preoperative surgical consent is crucial (3). A recent survey of 193 surgeons, all members of a professional association, The British Association of Endocrine and Thyroid Surgeons and of 415 patients via The Butterfly Thyroid Cancer Trust indicated that surgical practice was quite variable as regards consent and that patients would like to be consented for far more risks than they were currently informed about in general medical practice (23). This survey while very informative in some respects did not include specific questions directly related to issues of multidisciplinary working, diagnostic uncertainty, or lack of reproducibility in the diagnosis of thyroid cytology or histopathology (23). Based on the results of this survey, it is clear that there is a desire by patients for more information, hence more information regarding cytopathology and histopathology could be included in preoperative patient consent forms and in the preoperative consent process. As it is known for example that there is a false positive rate for malignancy of Thy 5/Bethesda Category VI in thyroid cytology of approximately $2 \%$ (1), there is a strong case for including issues that relate to imaging, cytopathology, histopathology and multidisciplinary discussion in the presurgical patient consent process also.

The third major issue in litigation for the UK is that most medical practice takes place in government funded hospitals and clinics, under the auspices of the UK National Health Service (NHS). The governments of England and the devolved jurisdictions of Wales, Scotland, and Northern Ireland fund a publicly insured scheme; The Clinical Negligence Scheme for NHS Trusts which is managed by a government body, NHS Resolution. In 2018/2019 claims for clinical negligence including damages, claimant and 
defense costs to NHS Resolution were $£ 2.36$ billion which represents approximately $1 \%$ to $2 \%$ of the total UK NHS healthcare budget (24).

Most claims for clinical negligence are undertaken on a 'no-win no-fee basis' which implies that lawyers will have expended considerable time dealing with the client's claim and therefore all aspects of the patient's clinical management are examined in granular detail to identify potential areas for claim.

This brief summary describes some of the current issues in clinical negligence in England at the time of writing this article and offers some suggestions to improve clinical information regarding thyroid cyto/histopathology provided to patients prior to thyroid procedures or to thyroid surgery.

\section{Acknowledgments}

Funding: None.

\section{Footnote}

Provenance and Peer Review: This article was commissioned by the Guest Editor (Kennichi Kakudo) for the series "Asian and Western Practice in Thyroid Pathology: Similarities and Differences" published in Gland Surgery. The article has undergone external peer review.

Conflicts of Interest: The author has completed the ICMJE uniform disclosure form (available at http://dx.doi. org/10.21037/gs.2020.02.15). The series "Asian and Western Practice in Thyroid Pathology: Similarities and Differences" was commissioned by the editorial office without any funding or sponsorship. The author has no other conflicts of interest to declare.

Ethical Statement: The author is accountable for all aspects of the work in ensuring that questions related to the accuracy or integrity of any part of the work are appropriately investigated and resolved.

Open Access Statement: This is an Open Access article distributed in accordance with the Creative Commons Attribution-NonCommercial-NoDerivs 4.0 International License (CC BY-NC-ND 4.0), which permits the noncommercial replication and distribution of the article with the strict proviso that no changes or edits are made and the original work is properly cited (including links to both the formal publication through the relevant DOI and the license).
See: https://creativecommons.org/licenses/by-nc-nd/4.0/.

\section{References}

1. Malheiros DC, Canberk S, Poller DN, et al. Thyroid FNAC: Causes of false-positive results. Cytopathology 2018;29:407-17.

2. Rosai J, Kuhn E, Carcangiu ML. Pitfalls in thyroid tumour pathology. Histopathology 2006;49:107-20.

3. Dent PC, Bagnall NM. Litigation in thyroid surgery in England. Br J Hosp Med (Lond) 2017;78:213-8.

4. Lloyd RV, Oamura RY, Kloppel G, et al. WHO classification of tumours of endocrine organs. Fourth Edition ed. IARC WHO Classification of Tumours. Lyon: IARC WHO, 2017.

5. Elsheikh TM, Asa SL, Chan JK, et al. Interobserver and intraobserver variation among experts in the diagnosis of thyroid follicular lesions with borderline nuclear features of papillary carcinoma. Am J Clin Pathol 2008;130:736-44.

6. Lloyd RV, Erickson LA, Casey MB, et al. Observer variation in the diagnosis of follicular variant of papillary thyroid carcinoma. Am J Surg Pathol 2004;28:1336-40.

7. Hirokawa M, Carney JA, Goellner JR, et al. Observer variation of encapsulated follicular lesions of the thyroid gland. Am J Surg Pathol 2002;26:1508-14.

8. Thompson LDR, Poller DN, Kakudo K, et al. An International Interobserver Variability Reporting of the Nuclear Scoring Criteria to Diagnose Noninvasive Follicular Thyroid Neoplasm with Papillary-Like Nuclear Features: a Validation Study. Endocr Pathol 2018;29:242-9.

9. Liu Z, Bychkov A, Jung CK, et al. Interobserver and intraobserver variation in the morphological evaluation of noninvasive follicular thyroid neoplasm with papillarylike nuclear features in Asian practice. Pathol Int 2019;69:202-10.

10. Fnais N, Soobiah C, Al-Qahtani K, et al. Diagnostic value of fine needle aspiration BRAF(V600E) mutation analysis in papillary thyroid cancer: a systematic review and metaanalysis. Hum Pathol 2015;46:1443-54.

11. Franc B, de la Salmoniere P, Lange F, et al. Interobserver and intraobserver reproducibility in the histopathology of follicular thyroid carcinoma. Hum Pathol 2003;34:1092-100.

12. Ezzat NE, Abusinna ES, Hafez NH, et al. Inter-observer reproducibility of the Royal College system for reporting thyroid cytology: Experience of the Egyptian National Cancer Institute. J Egypt Natl Canc Inst 2018;30:85-91.

13. Awasthi P, Goel G, Khurana U, et al. Reproducibility 
of "The Bethesda System for Reporting Thyroid Cytopathology:" A Retrospective Analysis of 107 Patients. J Cytol 2018;35:33-6.

14. Sheffield BS, Masoudi H, Walker B, et al. Preoperative diagnosis of thyroid nodules using the Bethesda System for Reporting Thyroid Cytopathology: a comprehensive review and meta-analysis. Expert Rev Endocrinol Metab 2014;9:97-110.

15. Gerhard R, Boerner SL. The value of second opinion in thyroid cytology: a review. Cancer Cytopathol 2014;122:611-9.

16. Cibas ES, Baloch ZW, Fellegara G, et al. A prospective assessment defining the limitations of thyroid nodule pathologic evaluation. Ann Intern Med 2013;159:325-32.

17. Kocjan G, Chandra A, Cross PA, et al. The interobserver reproducibility of thyroid fine-needle aspiration using the UK Royal College of Pathologists' classification system. Am J Clin Pathol 2011;135:852-9.

Cite this article as: Poller DN. Litigation in thyroid cytology and histopathology in England: a very brief overview. Gland Surg 2020;9(5):1648-1652. doi: 10.21037/gs.2020.02.15
18. Poller DN, Johnson SJ, Bongiovanni M. Measures to reduce diagnostic error and improve clinical decision making in thyroid fine-needle aspiration cytology. Cancer Cytopathol 2020. In Press.

19. Labarge B, Walter V, Lengerich EJ, et al. Evidence of a positive association between malpractice climate and thyroid cancer incidence in the United States. PLoS One 2018;13:e0199862.

20. Bolam v Friern Hospital Management Committee. 2 All ER 118; 1957.

21. Desmond Muller v King's College Hospital NHS Foundation Trust. High Court; 2017.

22. Montgomery v Lanarkshire Health Board. UK Supreme Court UKSC 112015.

23. McIntyre C, Tolley N. A critical review of thyroidectomy consent in the UK. Int J Surg 2019;66:84-8.

24. NHS Resolution. Annual report and accounts 2018/19 2019. 